\title{
Comparison of Immune Responses following Intradermal and Intramuscular Rabies Vaccination Methods
}

\author{
Mahsa Golahdooz ${ }^{1}$, Sana Eybpoosh ${ }^{2}$, Rouzbeh Bashar ${ }^{1}$, Mahsa Taherizadeh ${ }^{1}$, Behzad Pourhossein $^{3}$, \\ Mohammad Reza Shirzadi ${ }^{4}$, Behzad Amiri ${ }^{4}$, Maryam Fazeli ${ }^{*}$
}

\begin{abstract}
${ }^{1}$ Department of Virology, Pasteur Institute of Iran, Tehran, Iran; ${ }^{2}$ Department of Epidemiology and Biostatistics, Research Centre for Emerging and Reemerging Infectious Diseases, Pasteur Institute of Iran, Tehran, Iran;

32Department of Virology, School of Public Health, Tehran University of Medical Sciences, Tehran, Iran; ${ }^{4}$ Department of Zoonosis Control, Center for Communicable Diseases Control, Ministry of Health and Medical Education, Tehran, Iran
\end{abstract}

Received Jun. 10, 2018; Accepted Jun. 12, 2019

\begin{abstract}
Rabies is a zoonotic viral disease. The causative agent is a negative-sense RNA genome virus of the genus Lyssavirus (Family: Rhabdoviridae). The disease, commonly transmitted by rabid dogs, is the cause of mortality of over 59000 humans worldwide annually. This disease can be prevented before the development of symptoms through proper vaccination even after exposure. Hence, improvement of the vaccination schedule in the countries where rabies is endemic is essential. In addition to the type of vaccine, injection routes also contribute to enhanced immune responses and increased potency of the vaccines. The vaccines approved by the World Health Organization (WHO) include cell culture and embryonated egg-based rabies vaccines (CCEEVs). In order to develop a vaccine against rabies, it is necessary to use an appropriate delivery system to promote a proper antigen-specific immune response. Different routes of injection such as intradermal (ID), intramuscular (IM) or subcutaneous (SC) are practiced, with controversies over their suitability. In this article, we discuss the immunological aspects of rabies vaccination by comparing ID and IM delivery systems. J Med Microbiol Infec Dis, 2018, 6 (4): 77-86.
\end{abstract}

Keywords: Rabies Vaccine, Rabies, Immunization Schedule, Vaccination, Lyssavirus.

\section{INTRODUCTION}

Rabies is a zoonotic viral disease caused by a neurotropic virus. The virus has a non-segmented, singlestranded, negative-sense RNA genome and belongs to the genus Lyssavirus (Family: Rhabdoviridae) [1]. It is primarily transmitted to humans via the saliva of rabid animals after bite. Scratching or licking of mucous or wounds by rabid animals are the other routes of transmission [2, 3]. Unusual transmissions, such as solid organ transplantation and inhalation of contaminated aerosol (e.g., in bat-infested caves), have also been reported in some human rabies cases [3]. The disease is almost $100 \%$ fatal within two weeks following the appearance of clinical signs [4-6]. Annually, Rabies is responsible for 59000 human deaths, and over 3.7 million disability-adjusted life years (DALYs) lost. Children less than 15 years of age constitute almost $40 \%$ of exposures to suspected rabid animals [4].

Epidemiology. The rabies virus can infect humans, domestic, and wild animals, and has a significant impact on public health and the husbandry economy, especially in endemic regions [5-9]. The virus occurs across all parts of the world except Antarctica (Fig. 1) [10]. Approximately 20,000 human cases, which account for about one-third of annual rabies cases, occur in India, mostly through canine bites. Thus, in this country, the primary control measure has focused on the elimination of rabies in animals, mainly dogs [11]. A study in 2016, showed that rabies in many regions of China is still endemic and remains uncontrolled. In the northwest of China, rabies transmission to humans commonly occurs through the bite of stray dogs and foxes, and licensed vaccines for wildlife and large domestic animals are still required [12]. In Kazakhstan, despite mass animal vaccination, the disease is also endemic, causing substantial economic costs [13]. Sultanov et al. suggested that regular annual vaccination of domestic animals would be beneficial for the control of the disease [13]. In Ethiopia, where the canines are the primary vectors, about 2,700 annual human deaths occur due to rabies [13]. The annual cost of livestock loss due to rabies infection exceeds 50 million dollars in this country [14]. In Cambodia, Rabies has a high prevalence, especially in rural areas. Circulation of the virus among stray dogs in this country makes mass vaccination of these animals necessary [15].

\section{${ }^{*}$ Correspondence: Maryam Fazeli}

The National Center for Reference and Research on Rabies, Department of Virology, Pasteur Institute of Iran, Tehran, Iran, 1316943551.

Email: m_fazeli@pasteur.ac.ir

Tel: +98 (21) $66403496 \quad$ Fax: +98 (21) 64112813 
Epidemiological studies conducted in western, southeastern, eastern, and northeastern areas of Iran show a fluctuating trend in animal bite over recent years [16, 17]. In Western Europe and some Asian countries such as Singapore and Japan, mass vaccination of animals has dramatically controlled the disease in human and animal populations [18, 19]. In Eastern America, rabies is endemic among raccoons. Following detection of the first rabies cases in raccoons, oral vaccination was initiated in Long Island and New York and continued until complete elimination of rabies in the raccoon population [20]. In Northern Africa, the Middle East, Central Asia, and most European countries, dogs are the primary cause of rabies transmission, while in some Eastern European countries, such as Croatia and Serbia, foxes play the leading role in the disease epidemic [21].

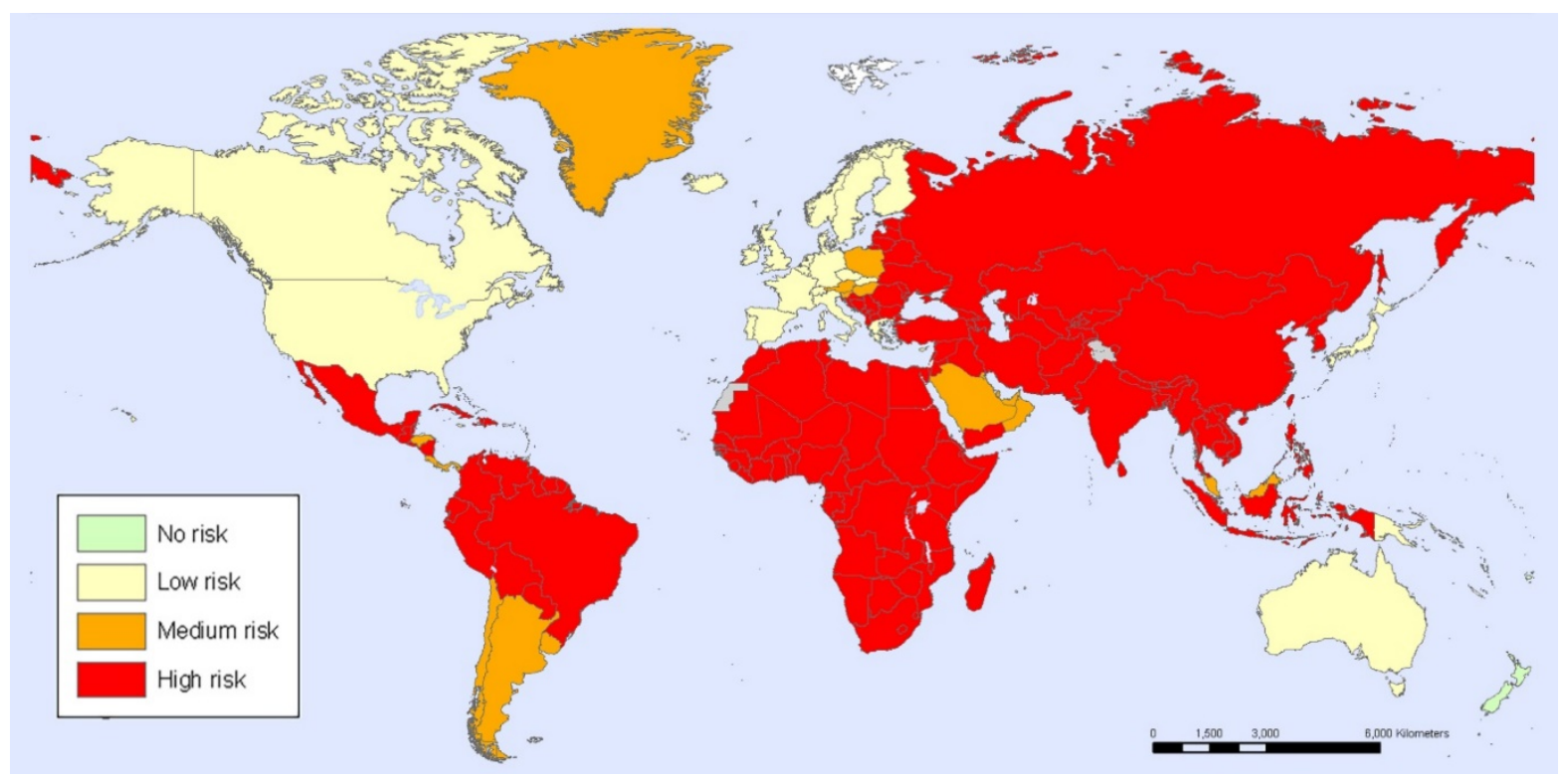

Fig. 1. Global distribution of rabies (WHO, 2013). No risk: there is no risk virus transmission; Low risk: pre-exposure immunization recommended for people who might come into contact with bats; Medium risk: pre-exposure immunization recommended for travelers and other people who might come into contact with bats and other wildlife; High risk: pre-exposure immunization recommended for travelers and other people who might come into contact with domestic animals particularly dogs and other rabies vectors [22].

Types of Rabies Vaccine. The first rabies vaccine was introduced in 1885 by Louis Pasteur using spinal cord tissue of infected (and necessarily dead) rabbits. However, this vaccine was abandoned later as it developed neuroparalytic complications in some patients [17]. Current rabies vaccines are categorized based on their origin, i.e., of tissue culture origin or embryonated egg origin. Currently, the World Health Organization (WHO) strongly recommends nerve tissue vaccines to be replaced by cell culture vaccines and embryonated egg-based rabies vaccines (CCEEVs) [1]. Cellular culture vaccines are widely used for vaccination of animals and humans and have a high potency of inducing immune responses [17, 23]. Today, purified Vero cell rabies vaccine (PVRV) is in use in Iran, and so far, no report of untoward effects in response to the vaccine is available [17, 24-26].

Today, DNA and recombinant vaccines, which often use glycoprotein "g" of the rabies virus, are also available, but WHO has not approved them yet. These vaccines, like cellular culture vaccines, could induce production of neutralizing antibodies [27]. Galvez-Romero et al. demonstrated that the DNA vaccine, the G5 polypeptide linear epitope, triggered the production of neutralizing antibodies. The G5 glycoprotein fused to the molecular adjuvant C3dP28 increased proliferation of specific $\mathrm{TCD}_{4+}$ and $\mathrm{TCD}_{8^{+}}$against rabies in the spleen of mice. The addition of the C3d-P28 adjuvant showed to result in the development of a series of immune responses, such as the sustained production of virus-neutralizing antibodies (VNAs), and a specific T-cell proliferative response [28]. Another structure, used in 1987, included the rabies virus ribonucleoprotein (RNP). This structure could produce protective immune responses against lethal challenge with rabies and rabies-related lyssaviruses in animals [29]. In many countries, especially in Europe, oral rabies vaccines are currently used in wildlife to eliminate rabies in a geographically limited area [30].

Immunological features of rabies virus and vaccines. In most human rabies cases, 7-10 days after the onset of clinical symptoms, no significant pathological lesions occur in the central nervous system, and there is no significant immune response in this period as well. The way the virus remains at the inoculation site and why it does not trigger the host's immune response is not well understood yet [31]. It is also unclear if the street rabies virus, mouse-adapted rabies virus, and tissue culture-adapted rabies virus replicate on the inoculum site before attacking the central nervous system (CNS). Current knowledge about the host's immune response against the rabies virus has mainly resulted from the experimental and laboratory-based studies. Few studies have been conducted on wild animals, vaccinated dogs, or humans [32]. 
Innate immunity. The innate immune response provides the first line of defense against the infectious agents. These immune responses encounter pathogens in the early hours of entering the body and are not specific to the pathogens. The CNS cells via unique antiviral defense mediated by pathogen recognition receptors (PRRs) detect danger signals, and pathogen-associated molecular pattern (PAMP) that expressed by pathogens can detect rabies virus RNA. Existing evidence suggests that Toll-Like Receptors (TLRs) are among the best PRRs in the innate immune response against the rabies virus. Some TLRs occur on the cell membrane, and some others are inside the cell. There are 10, and 12 functional TLRs in the human (TLR1-10), and mice, respectively [33]. The peripheral nerve plexus and sensory nerve fibers in the spinal dorsal horn and sciatic nerve are capable of expressing TLR3, and sometimes TLR 4 and TLR 7 receptors [34, 35]. The expressed TLR3 binds to ssRNA, which can detect RNA of the rabies virus. Experimental studies also have revealed that TLR3-deficient mice are less susceptible to the rabies virus infections. These observations suggest that
TLR3 may have an active role in the pathogenesis of rabies virus [36-38].

The RIG-like receptor (RLR) is a signaling pathway that runs for the production of interferon type I (IFN $\alpha$ and IFN $\beta$ ). This pathway eliminates the virus-infected cells by the control of protein expression and stimulation of the adaptive immune system. RLRs only affect the viral RNA present in the cytoplasm and encode the triphosphate group in the 5' end. The result of signal transduction is the deployment of TRIF, Myd88, and IPS- 1 as TLRs and RLRs adapters. They induce expression of the interferonstimulating genes as the first line of defense against viral infection (Fig. 2) [38-40]. The importance of innate immunity against rabies has been documented in some animal models. Some studies have shown that IFN receptor (IFNAR-I)-deficient mice exhibit an increase in viral load and morbidity when exposed to rabies infection. In fact, the growth of the rabies virus reduces in cells that have a functional system of interferon type I [41].

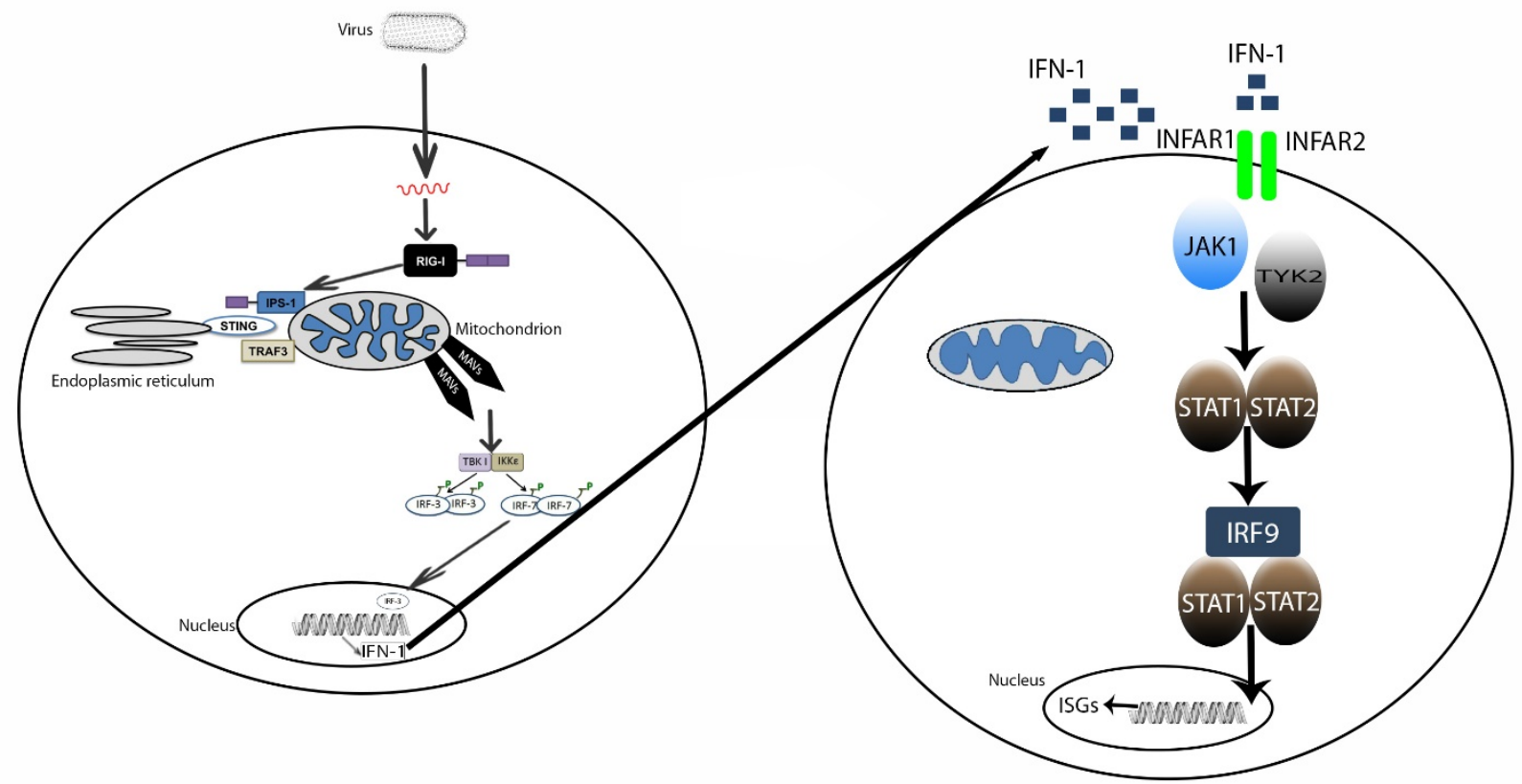

Fig. 2. Schematic diagram of the IFN signaling pathways induced by IFN-1. RLR, RIG-Like Receptor; RIG-1, Retinoic Acid-Inducible Gene-1; MAVs, Mitochondria Antiviral Signaling Protein; TBK-1, Serin-Threonine Protein Kinase-1; IRF-9, Interferon Regulatory Factor-9; JAK-1, Janus Kinase-1; STAT, Signal Transducers and Activator of Transcription; ISG, Interferon Stimulated Gene.

Another protective mechanism of innate immunity against viruses is autophagy. For rabies and most of the neurotropic viruses, the autophagy contributes by trapping the virus (as an external molecule) into autophagosomes followed by their degradation in the neurons and other postmitotic cells [36, 37]. In summary, the dysfunction of autophagy is linked with the propagation of viral infectious diseases.

Some researchers suggest that regulatory mechanisms during the rabies infection period are established to reduce the induction of inflammation of the nervous system. The limitation of the inflammation by rabies virus infection may occur by 1) reduction of leukocytes, monocytes, and macrophages entrance into the nerve tissue, 2) the inability of most immune cells to cross the blood-brain barrier (BBB) and 3) Minimizing the release of neurotoxic molecules which is essential for the continued function of the nervous system and host survival. These conditions not only preserve the integrity of the infected neurons but also preserve the host's life, so that the virus can spread to 
Medulla oblongata and salivary glands before the premature death of the infected host [38, 39].

Adaptive immune response. The second line of defense, which acts after innate immunity, is adaptive immunity. Commonly, virus-infected cells are suppressed and cleared by cellular and humoral immune responses as part of the adaptive immune system. Following inoculation of the rabies vaccine, the innate immunity uptakes and degrades the vaccine antigens before presenting them to the lymph nodes. The process occurs through antigen providing cells (APCs). The adaptive immune response against a microorganism never occurs in the brain due to anatomical features of the brain, i.e., absence of conventional lymphatic drainage, and scarcity of DCs. This is the case for neurotropic viruses which quickly enter the nerve tissue after inoculation into the muscle.

Humoral immune response. Although the humoral immune response is a late-phase response against viral infections, it plays a vital role in combating these infections [34, 35] including rabies virus infection. Rabies virus propagation occurs by budding into synapses and being taken up across the postsynaptic membrane. The virus can cross the blood-brain barrier (BBB) and evade immune surveillance. To effectively protect against rabies, the virus must be prevented from entering the peripheral nerves at the lesion site, which does not occur in individuals with the low antibody titers. In the absence of Immunoglobulin G (IgG), the virus enters the peripheral nerves and then manages to enter the CNS. Therefore, adequate levels of neutralization antibodies should be available to control the infection [34, 40]. During the infection, it is unknown whether the antigens that control the antibody response are from the viruses in the periphery or CNS. In a Syrian hamster model of rabies virus infection, the IgG2 antibody was diagnosed early on the fifth day of the challenge [35]. Some studies acknowledged that rabies vaccines induce the production of class $G$ antibodies through the conversion of primary follicles into germinal centers and secondary follicles into lymph nodes [34, 35, 40]. Immediate disinfection of the wound following animals bite as well as immunoglobulin and vaccine therapies are necessary procedures to assist the immune system in neutralizing the virus.

Cell-mediated immune response. As an effective immune response against viral infections, the primary role of Cytotoxic T-Lymphocyte (CTL) cells is to clear the infection by killing virus-infected cells. Pathogenic strains of the rabies virus, however, suppress the cell-mediated immune response through different pathways [34, 35]. A critical feature of the rabies virus is that it reduces the infiltration of T-cells in the host's CNS. The virus also stimulates apoptosis of TCD8+ cells, which helps the virus in escaping the cellular immune system. In vivo studies have demonstrated the effect of rabies infection on the degradation/tiredness of $\mathrm{T}$ cells in the nervous system of infected mice [40, 41]. Destruction of the immune cells occurs in a way that the CD4/CD8 ratio remains constant. Evidence also suggests the expression of particular cytokines, namely IL-6 and IL-12, in Rabies virus-infected neurons [40, 41].
Durability and stability of antibodies against rabies virus after vaccination. As mentioned previously, the WHO strongly recommends CCEE vaccines instead of nerve tissue vaccines (NTVs). According to the WHO guidelines, all CCEE vaccines should have a potency of $\geq 2.5$ international units (IU) per single dose of intramuscular (IM) injection ( $\geq 2.5 \mathrm{IU} / \mathrm{IM}$ dose) [42]. The minimum post-vaccination neutralizing antibody titer acceptable by WHO and OIE for human and animal is $\geq 0.5$ $\mathrm{IU} / \mathrm{ml}$ [42].

After inoculation of the rabies vaccine, neutralizing antibodies are produced against the virus due to the participation of the $\mathrm{TH}$ cells. The vaccine does not have a significant effect on the activity of CTL cells, and may even damage them [43]. Generally, the immunity duration in a person after the first injection of rabies vaccine depends on various factors including recipient's age and gender, as well as the vaccine's immunogenicity level, type and injection route [44]. In 1987, a study indicated that most CCEEVs maintain detectable neutralizing antibody after preexposure prophylaxis for as long as 5 years, and then a single booster dose evokes an excellent antibody response [45]. Rabies CCEEVs can develop long-lasting immunity, and a single booster dose will result in an anamnestic response.

In a study in 1991, the use of rabies virus RNP for the pre-exposure prophylaxis in monkeys was investigated. After two inoculations, the monkeys rapidly developed a robust anti-RNP response and showed protection against infection when challenged with a lethal dose of the street virus. The study also indicated that antibody titers in monkeys who were primed with RNP and then immunized with a single dose of HDCV were comparable to VNA titers in monkeys immunized twice with the HDCV vaccine [46]. In 1998, rabies DNA vaccine in nonhuman primates elicited a highly protective immune response against the virus and showed promising for human rabies vaccination [47]. The stability and low-cost production of DNA vaccines make them suitable candidates for mass rabies vaccination in resource-limited countries.

Lodmell et al. compared the neutralizing antibody responses in mice after priming and boosting with three different types of vaccine and showed long-term levels of neutralizing antibody in response to the first injection of three vaccines, i.e., DNA vaccine, recombinant vaccinia virus (RVV) vaccines encoding $G$ and HDCV. In contrast, they elicited immune responses differently in booster injection [48]. Lodmell et al. also studied the persistence of the neutralizing antibodies of rabies DNA vaccine in dogs and showed that one single dose of intradermal vaccine delivered via the ear pinnae of dogs resulted in neutralizing antibody against rabies. Such interventions can be considered for vaccination of dogs, especially in resource-limited countries [49].

In a systematic review, Morris et al. reviewed the evidence for current UK policy on rabies booster vaccination. They suggested reducing the currently recommended interval to the first booster from two years to one year. Although, further research with a longer follow- 
up duration is required to make recommendations for subsequent boosters [50]. Another study suggested that tissue culture rabies vaccine, as recommended by WHO, can develop long-term immunity in vaccinated individuals, and the booster dose only in the absence of immunoglobulin could elicit adequate immunogenicity, even in people vaccinated more than five years ago [51]. Intradermal administration of a single dose of rabies DNA vaccine, encoding glycoprotein, in-ear pinnae of dogs showed protection against rabies infection for one year and suggested a new approach for controlling endemic canine rabies in developing countries [52]. The antibody titer in high-risk individuals should be measured one year after the vaccination, and when the serological assay is no available, a booster dose regardless of their antibody levels is recommended [53]. A study on 45 individuals who had received a single dose of HDCV vaccine following exposure to dogs and wolves during 1975-1976 showed a detectable antibody titer even 32 years after initial postexposure prophylaxis (PEP) [54].
Indications for human rabies vaccination. According to the WHO recommendation, individuals at-risk of rabies infection, including lab-workers in the field of rabies, veterinarians, veterinary students, wildlife workers, dog breeders, and animal handlers should receive rabies PrEP. Also, PEP, including vaccine and immunoglobulin, should be provided to individuals exposed to suspicious animals [22]. In a study in 2013, showed that in endemic regions, it is crucial to choose an immunization method which develops long-lasting immunological memory for children at the high risk of exposure to rabid animals [55]. Table 1 provides indications for post-exposure rabies prophylaxis (PEP) by the category of exposure. For people who had already received pre-exposure cell-culture vaccines via either IM or ID routes, two doses of these vaccines will be sufficient in days first and third after exposure. In these cases, there is no need for the injection of anti-rabies serum [56-58].

Table 1. Indications for post-exposure rabies prophylaxis (PEP) by category of exposure

\begin{tabular}{|c|c|}
\hline Exposure Category Type & Recommendations \\
\hline \multicolumn{2}{|c|}{ Immunologically naive individuals of all age groups } \\
\hline Category I & $\begin{array}{l}\text { Washing of exposed skin surfaces. } \\
\text { No PEP required. }\end{array}$ \\
\hline Category II & $\begin{array}{l}\text { Wound washing and immediate vaccination: } \\
\text { 2-sites ID on days } 0,3 \text { and } 7 \\
\text { OR } \\
1 \text {-site IM on days } 0,3,7 \text { and between day 14-28 } \\
\text { OR } \\
\text { 2-sites IM on days } 0 \text { and 1-site IM on days 7, } 21 \\
\text { RIG is not indicated. }\end{array}$ \\
\hline Category III & $\begin{array}{l}\text { Wound washing and immediate vaccination } \\
2 \text {-sites ID on days } 0,3 \text { and } 7 \\
\text { OR } \\
1 \text {-site IM on days } 0,3,7 \text { and between day 14-28 } \\
\text { OR } \\
\text { 2-sites IM on days } 0 \text { and } 1 \text {-site IM on days 7, } 21 \\
\text { RIG administration is recommended. }\end{array}$ \\
\hline \multicolumn{2}{|c|}{ Previously immunized individuals of all age groups } \\
\hline Category I & $\begin{array}{l}\text { Washing of exposed skin surfaces. } \\
\text { No PEP required. }\end{array}$ \\
\hline Category II & $\begin{array}{l}\text { Wound washing and immediate vaccination:* } \\
1 \text {-site ID on days } 0 \text { and } 3 \\
\text { OR } \\
\text { At } 4 \text {-sites ID on day } 0 \\
\text { OR } \\
\text { At } 1 \text {-site IM on days } 0 \text { and } 3 \\
\text { RIG is not indicated. }\end{array}$ \\
\hline Category III & $\begin{array}{l}\text { Wound washing and immediate vaccination:* } \\
1 \text {-site ID on days } 0 \text { and } 3 \\
\text { OR } \\
\text { At } 4 \text {-sites ID on day } 0 \\
\text { OR } \\
\text { At } 1 \text {-site IM on days } 0 \text { and } 3 \text { RIG is not indicated. }\end{array}$ \\
\hline
\end{tabular}

* Immediate vaccination is not recommended if complete PEP already received within the past 3 months or earlier.

Vaccination routes. Rabies vaccines are delivered via various routes, including IM, ID, subcutaneous (SC), Intracerebral (IC), oral, and intranasal. IM injection technique is currently the most commonly used routes worldwide.

Oral vaccination. Rabies control and prevention in wildlife, especially in Europe, relies on oral vaccination. In Germany, oral vaccination of foxes was initiated in 1985 and continued until the elimination of rabies in foxes. Follow-up studies in this region showed that a single-dose oral vaccination immunized around $75 \%$ of the fox population. Oral vaccination is in agreement with the animal welfare laws [59], and due to its effectiveness, safety, low cost, and ease of application is a practical approach to control and eliminate rabies in the wildlife.

IM injection. Currently, both types of IM and ID injections are available against the rabies virus, while the former is in more practice. In the IM method, one ml of the vaccine is inoculated into the muscle. The recommended injection site in adults and children of two years age and 
older is the deltoid muscle, and in younger children, the anterolateral muscle [56]. The IM method can be used for both PrEP and PEP, making it applicable for both treatment and prevention purposes. A prominent disadvantage of this method is the need for more vaccine material comparing to the ID method. This flaw results in increased cost of vaccination and makes this method less appropriate for mass immunization programs. The new proposed regimen by WHO is presented in Table 1 [56].

ID injection. In the ID method, $0.1 \mathrm{ml}$ of the vaccine (CCEEVs vaccine with the recommended potency) is injected in the dermis (irrespective of the vaccine brand; see Table 1) [48]. The method showed to be effective in many studies. In a study, three ID doses of PCECV (on day 0, 7, and 21) elicited an appropriate immunization against rabies in 5-10 years old children [55]. In another study, a first IM injection followed by a booster ID injection showed an adequate immune response in preventing rabies [60]. In a prospective study, Vero cell vaccine was injected through both IM and ID. The results showed that both methods produced appropriate immune responses [61].

The ID method is recommended in developing countries for both PrEP and PEP practices due to two reasons: 1) the dose consumed in this method is $1 / 10$ of the IM method, making it less expensive [5], 2) evidence and immunologic findings suggest that the method results in a better immune response than IM, i.e., the immune system release more neutralizing antibody rapidly through this type of injection [56]. Therefore, the method seems to be a cost-effective choice for low-income and developing countries. For these reasons, ID method has been in practice in endemic regions of Africa in the past three decades [62]. Mills et al. also reported that the ID injection of rabies vaccine was the right choice for individuals who travel to endemic areas. However, it should be noted that the ID method is not recommended for the settings where trained personnel are not available [63]. Under these situations, especially when the individual does not intend to travel, IM injection is preferred over the ID method.

Other routes. Studies on mouse models show that all vaccination routes, i.e., IM, SC, and IC illicit immune responses, but neutralizing antibody titers in blood plasma were seen significantly with the highest levels in IC immunized mice [64]. A study in 2010 showed that IC injection induces humoral immunity response after production of neutralizing antibody in the CSF fluid. An essential advantage of the method is that it can be used for both animals and humans [65]. The last vaccination route is mucosal immunization, which is a non-invasive technique. Mucosal adjuvant of inactivated rabies antigen delivered through the human nasal cavity has shown as an effective method for increasing immunity level [66].

IM versus ID vaccination. Today, WHO recommends the use of the cell culture-derived rabies vaccines [42]. Immunogenicity of cell culture vaccines has shown to be higher than vaccines produced in the animal brain tissues [67]. Due to the higher cost of cell culture vaccines, nervous tissue vaccines are still used in some countries. Other vaccines, such as DNA vaccines, have also been introduced that are more immunogenic and less expensive than cell culture vaccines. These types of vaccines can especially be suitable for resource-limited countries.

There is a controversy over the superiority of vaccination routes including IM and the ID. Here, we discuss significant advantages and disadvantages of the two methods in four domains: 1) consumed dose, 2) site of injection, 3) vaccination regime and 4) extent of the immune response.

Consumed dose. The low dose and the reduced cost per injection of ID method make it the right choice for vaccination, especially in resource-limited countries. Rabies vaccines are available in $1 \mathrm{ml}$ vials. Hence, in the IM method, one vial suffices for vaccination of only one individual, while in the ID method, the same amount can be used for vaccination of the 10 persons. In areas where the animal bite occurs sporadically, IM method is preferable, as an opened vial cannot be preserved for a long time [56].

Site of injection. IM rabies vaccine is injected in the deltoid muscle. By this route, the vaccine is slowly absorbed from the gluteal area due to high-fat content in this body part, which results in a slower immune response compared to the ID. However, IM injection is more comfortable than ID injection and can be performed by staffs with the medium-level skill [41, 68]. As mentioned previously, in settings where trained personnel are not available, IM injection is preferable over the ID method [63].

Type of recommended regimen. Generally, in the IM method, anti-rabies cell culture vaccines require five doses on days $0,3,7,14$, and 28 . While, due to the higher induced immunogenicity by the ID route, fewer doses would suffice. The ID method is expected to increase the individuals' compliance with the vaccination regimen as they are not required to refer to the health centers for vaccination repeatedly, which is a great advantage [69].

Extent of the immune response. Considering the immunologic process described above, the antigens that enter the skin at their optimal dose can stimulate the immune system with higher speed and intensity. They also induce germinal centers in lymphatic nodes of the skin, especially the ones close to the injection site, and lead to the production of regional neutralizing antibodies, which results in a more stable and lasting response [70]. A recent report by WHO showed that APCs in the skin were responsible for the development of a robust immune response following ID vaccination $[56,58]$. So, providing a more prominent and long-lasting antibody response can be considered as the superiority of the ID method over the IM method.

Development of Immunological responses following ID injection. The dose and the site of antigen introduction into the body have a profound effect on the immunogenicity of an antigen. Skin is considered as an immune organ because it acts as a mechanical-physical barrier against external agents. The skin is also equipped with a robust immune system, which can induce both humoral and cellular immune responses. Around $2-4 \%$ of the epidermis 
cells are composed of dendritic cells [71]. These cells originated from the bone marrow, comprised a large family of APCs in the mammalian immune system. They constitute three significant subclasses based on tissue that involved them: Langerhans cells (LC), interdigitating dendritic cells (IDC), and follicular dendritic cells (FDC) $[72,73]$. The skin also has access to the lymph nodes.

After entering of the rabies vaccine antigen into the skin, the Langerhans cells which are a type of APCs in the epidermis, transfer it to the lymph nodes and stimulate the production of neutralizing antibodies [71]. Cells enter the lymphatic vessel, and by moving toward a lymph node, antigen processing continues. During this process, the first extensive changes occur in the morphology of these naive APCs along with an increase in major histocompatibility complex (MHC) class II level of the cells. Eventually, cells demonstrate linear peptide on MHC II molecules as a stimulating epitope. After entering the lymph node, the epitope is presented to specific T-cells [72, 74, 75]. Unlike B-cells, T-cells are unable to identify free antigens. They can only identify linear peptides on MHC molecules and supply by APCs [75].

Some studies have shown that Langerhans cells cause stimulation of $\mathrm{T}$ follicular helper (TFH) cells and development of strong responses in the germinal center of lymph nodes, and if these cells are removed, the germinal center formation will be impossible. In the germinal center, a neutralizing antibody is eventually produced against the antigen [76].

In the ID method, memory B-cells and plasma cells with a long lifespan are produced, and the neutralizing antibody is synthesized rapidly against the antigen [76]. So, it can be implied that ID vaccination is associated with enhanced immunogenicity.

Conclusion and recommendations. Rabies virus has particular strategies to escape the immune system. However, the infection process can be controlled through proper and timely post-exposure vaccination. There are several vaccination and treatment approaches, which should be selected according to epidemiological and economic considerations. In resource-limited countries, it seems that delivery of vaccine via the ID route is more economical and efficient. This method also induces an immediate and longlasting immunity, which makes it a suitable choice for endemic regions. However, in non-endemic regions where exposure to rabid animals is not common, and in settings where expert staff are not available to perform ID injection, the IM method is preferable. Production of the cell culture vaccine in $0.1 \mathrm{ml}$ vials can prevent vaccine waste when the ID route (which uses a dose of $0.1 \mathrm{ml}$ per injection) is practiced.

\section{ACKNOWLEDGMENT}

The authors would like to acknowledge the staffs of the National Center for Reference and Research on Rabies, Virology Department, Pasteur Institute of Iran for their kind assistance and cooperation.

\section{CONFLICT OF INTEREST}

The authors declare that there are no conflicts of interest associated with this manuscript.

\section{REFERENCES}

1. Madhusudana SN, Subha S, Thankappan U, Ashwin YB. Evaluation of a direct rapid immunohistochemical test (dRIT) for rapid diagnosis of rabies in animals and humans. Virologica Sinica. 2012; 27 (5): 299-302.

2. Wilde H, Hemachudha T, Jackson AC. management of human rabies. Trans R Soc Trop Med Hyg. 2008; 102 (10): 979-82.

3. Dietzschold B, Faber M, Schnell MJ. New approaches to the prevention and eradication of rabies. Expert Rev Vaccines. 2003; 2 (3): 399-406.

4. Parmar D, Vora D, Rathod P, Narlawar U. Epidemiological profile of animal bite cases attending Anti rabies clinic and pretreatment practices adopted by them following animal bite: A cross-sectional study. Int J Med Health Res. 2016; 2 (4): 11-3.

5. Sridhar N, Kiran BS, Rudrapal M. Management, Postexposure Prophylaxis and Treatment of Dog Bites and Rabies Cases in a Tertiary Care Hospital. Biosci Biotech Res Asia. 2013; 10 (1):361-364

6. Wieten R, Tawil S, Van Vugt M, Goorhuis A, Grobusch M. Risk of rabies exposure among travellers. Neth J Med. 2015; 73: 219-26.

7. Fisher CR, Streicker DG, Schnell MJ. The spread and evolution of rabies virus: conquering new frontiers. Nat Rev Microbiol. 2018.

8. Srithayakumar V, Sribalachandran H, Rosatte R, Nadin-Davis SA, Kyle CJ. Innate immune responses in raccoons after raccoon rabies virus infection. J Gen Virol. 2014; 95 (1): 16-25.

9. Fazeli M, Golahdouz M, Bashar R, Arab Baferani M, Doosti Irani A, Pourhossein B, et al. Design and Validation of a Persian Knowledge, Attitude, and Practice Questionnaire for Rabies (PKAP-Rabies) in the General Population of Iran. J Med Microbiol Infect Dis. 2018; 6 (2): 67-71.

10. Organization WH. WHO expert consultation on rabies: third report. 2018.

11. Liu Y, Zhang H-P, Zhang S-F, Wang J-X, Zhou H-N, Zhang $\mathrm{F}$, et al. Rabies outbreaks and vaccination in domestic camels and cattle in northwest China. PLoS Negl Trop Dis. 2016; 10 (9): e0004890.

12. Sultanov AA, Abdrakhmanov SK, Abdybekova AM, Karatayev BS, Torgerson PR. Rabies in Kazakhstan. PLoS Negl Trop Dis. 2016; 10 (8): e0004889.

13. Coetzer A, Kidane A, Bekele M, Hundera A, Pieracci E, Shiferaw M, et al. The SARE tool for rabies control: Current experience in Ethiopia. Antiviral Res. 2016; 135: 74-80.

14. Ponsich A, Goutard F, Sorn S, Tarantola A. A prospective study on the incidence of dog bites and management in a rural Cambodian, rabies-endemic setting. Acta tropica. 2016; 160: 627. 
15. Dehghani R, Sharif A, Madani M, Kashani HH, Sharif MR. Factors influencing animal bites in Iran: a descriptive study. Osong Public Health Res Perspect. 2016; 7 (4): 273-7.

16. Shirzadi MR. A Comparative Study on the Adverse Reactions of Purified Chick Embryo Cell Vaccine (PCECV) and Purified Vero Cell Rabies Vaccine (PVRV). Arch Iran Med. 2016; 19 (7): 502.

17. Elser JL, Bigler LL, Anderson AM, Maki JL, Lein DH, Shwiff SA. The economics of a successful raccoon rabies elimination program on Long Island, New York. PLoS Negl Trop Dis. 2016; 10 (12): e0005062.

18. Hampson K, Dushoff J, Bingham J, Brückner G, Ali Y, Dobson A. Synchronous cycles of domestic dog rabies in subSaharan Africa and the impact of control efforts. P Natl Acad Sci. 2007; 104 (18): 7717-22.

19. Fu Z. The rabies situation in Far East Asia. Dev Biol. 2008; 131: 55-61.

20. Picot V, Rasuli A, Abella-Rider A, Saadatian-Elahi M, Aikimbayev A, Barkia A, et al. The Middle East and Eastern Europe rabies Expert Bureau (MEEREB) third meeting: LyonFrance (7-8 April, 2015). J Infect Public Health. 2017; 10 (6): 695-701.

21. Organization WH. WHO expert consultation on rabies: second report: World Health Organization; 2013.

22. Nandi S, Kumar M. Development in immunoprophylaxis against rabies for animals and humans. Avicenna J Med Biotechnol. 2010; 2 (1): 3.

23. Favi M, Yung V, Roos O, Rodriguez L, Trujillo R, Acevedo A. Immune response of suckling mouse brain (CRL) rabies vaccine and tissue culture rabies vaccine (Verorab) in preexposure prophylaxis in humans. Revista medica de Chile. 2004; 132 (1): 41-6.

24. Kulkarni PS, Sapru A, D’costa PM, Pandit A, Madhusudana $\mathrm{SN}$, Yajaman $\mathrm{AB}$, et al. Safety and immunogenicity of a new purified vero cell rabies vaccine (PVRV) administered by intramuscular and intradermal routes in healthy volunteers. Vaccine. 2013; 31 (24): 2719-22.

25. Malerczyk C, Briggs DJ, Dreesen DW, Banzhoff A. Duration of immunity: an anamnestic response 14 years after rabies vaccination with purified chick embryo cell rabies vaccine. J Travel Med. 2007; 14 (1): 63-4.

26. Andersson C. Production and delivery of recombinant subunit vaccines: Bioteknologi; 2000.

27. Galvez-Romero G, Salas-Rojas M, Pompa-Mera EN, Chávez-Rueda K, Aguilar-Setién Á. Addition of C3d-P28 adjuvant to a rabies DNA vaccine encoding the G5 linear epitope enhances the humoral immune response and confers protection. Vaccine. 2018; 36 (2): 292-8.

28. Dietzschold B, Wang H, Rupprecht CE, Celis E, Tollis M, Ertl $\mathrm{H}$, et al. Induction of protective immunity against rabies by immunization with rabies virus ribonucleoprotein. Proc Natl Acad Sci. 1987; 84 (24): 9165-9.

29. Baer GM. The natural history of rabies: CRC press; 1991.
30. Smreczak M, Zmudzinski J. Rabies control in wildlife with oral vaccination in Poland. Bulletin-Veterinary Institute in Pulawy. 2005; 49 (3): 255.

31. Barton GM, Medzhitov R. Toll-like receptor signaling pathways. Science. 2003; 300 (5625): 1524-5.

32. Wang ZW, Sarmento L, Wang Y, Li X-q, Dhingra V, Tseggai $\mathrm{T}$, et al. Attenuated rabies virus activates, while pathogenic rabies virus evades, the host innate immune responses in the central nervous system. J Virol. 2005; 79 (19): 12554-65.

33. Carty M, Reinert L, Paludan SR, Bowie AG. Innate antiviral signalling in the central nervous system. Trends Immunol. 2014; 35 (2): 79-87.

34. Johnson N, Cunningham AF, Fooks AR. The immune response to rabies virus infection and vaccination. Vaccine. 2010; 28: 3896-901.

35. Nair S, Diamond MS. Innate immune interactions within the central nervous system modulate pathogenesis of viral infections. Curr Opin Immunol. 2015; 36: 47-53.

36. Cuervo AM, Bergamini E, Brunk UT, Dröge W, Ffrench M, Terman A. Autophagy and aging: the importance of maintaining" clean" cells. Autophagy. 2005; 1 (3): 131-40.

37. Reinke SN, Resch L, Maingat F, Branton W, Jackson AC, Holt R, et al. Metagenomic and metabolomic characterization of rabies encephalitis: new insights into the treatment of an ancient disease. J Infect Dis. 2012; 207 (9): 1451-6.

38. Johnson $\mathrm{N}$, Cunningham AF. Interplay between rabies virus and the mammalian immune system. World J Clin Infect Dis. 2015; 5 (4): 67-76.

39. Dietzschold B, Kao M, Zheng YM, et al. Delineation of putative mechanisms involved in antibody-mediated clearance of rabies virus from the central nervous system. Proc Natl Acad Sci. 1992; 89: 7252-6.

40. Rouse BT, Sehrawat S. Immunity and immunopathology to viruses: what decides the outcome? Nat Rev Immunol. 2010; 10 (7): 514 .

41. mondiale de la Santé O, Organization WH. Weekly Epidemiological Record, 2018, vol. 93, 16 [Full issue]. Weekly Epidemiological Record= Relevé épidémiologique hebdomadaire. 2018; 93 (16): 201-20.

42. Khawplod P, Wilde H, Yenmuang W, Benjavongkulchai M, Chomchey P. Immune response to tissue culture rabies vaccine in subjects who had previous postexposure treatment with Semple or suckling mouse brain vaccine. Vaccine. 1996; 14 (16): 1549-52.

43. Berndtsson LT, Nyman A-KJ, Rivera E, Klingeborn B. Factors associated with the success of rabies vaccination of dogs in Sweden. Acta Vet Scand. 2011; 53 (1): 22.

44. Rodrigues F, Mandke V, Roumiantzeff M, Rao CM, Mehta J, Pavri K, et al. Persistence of rabies antibody 5 years after preexposure prophylaxis with human diploid cell antirabies vaccine and antibody response to a single booster dose. Epidemiol Infect. 1987; 99 (1): 91-5. 
45. Tollis M, Dietschold B, Volia CB, Koprowski H. Immunization of monkeys with rabies ribonucleoprotein (RNP) confers protective immunity against rabies. Vaccine. 1991; 9 (2): 134-6.

46. Lodmell DL, Ray NB, Parnell MJ, Ewalt LC, Hanlon CA, Shaddock JH, et al. DNA immunization protects nonhuman primates against rabies virus. Nat Med. 1998; 4 (8): 949-52.

47. Lodmell DL, Ewalt LC. Rabies vaccination: comparison of neutralizing antibody responses after priming and boosting with different combinations of DNA, inactivated virus, or recombinant vaccinia virus vaccines. Vaccine. 2000; 18 (22): 2394-8.

48. Lodmell DL, Parnell MJ, Weyhrich JT, Ewalt LC. Canine rabies DNA vaccination: a single-dose intradermal injection into ear pinnae elicits elevated and persistent levels of neutralizing antibody. Vaccine. 2003; 21 (25-26): 3998-4002.

49. Morris J, Crowcroft N. Pre-exposure rabies booster vaccinations: a literature review. Dev Biol. 2006; 125: 205-15.

50. Suwansrinon K, Wilde $\mathrm{H}$, Benjavongkulchai $\mathrm{M}$, Banjongkasaena U, Lertjarutorn S, Boonchang S, et al. Survival of neutralizing antibody in previously rabies vaccinated subjects: a prospective study showing long lasting immunity. Vaccine. 2006; 24 (18): 3878-80.

51. Lodmell DL, Ewalt LC, Parnell MJ, Rupprecht CE, Hanlon CA. One-time intradermal DNA vaccination in ear pinnae one year prior to infection protects dogs against rabies virus. Vaccine. 2006; 24 (4): 412-6.

52. Lim PL, Barkham TM. Serologic response to rabies preexposure vaccination in persons with potential occupational exposure in Singapore. Int J Infect Dis. 2010; 14 (6): e511-e3.

53. Fayaz A, Simani S, Janani A, Farahtaj F, Biglari P, Howeizi $\mathrm{N}$, et al. Antibody persistence, 32 years after post-exposure prophylaxis with human diploid cell rabies vaccine (HDCV). Vaccine. 2011; 29 (21): 3742-5.

54. Schneider L, Cox J, Müller W, Hohnsbeen K-P. Current oral rabies vaccination in Europe: an interim balance. J Infect Dis.

55. Madhusudana SN, Mani RS. Intradermal vaccination for rabies prophylaxis: conceptualization, evolution, present status and future. Expert Rev Vaccines. 2014; 13 (5): 641-55.

56. Khawplod P, Wilde H, Chomchey P, Benjavongkulchai M, Yenmuang W, Chaiyabutr N, et al. What is an acceptable delay in rabies immune globulin administration when vaccine alone had been given previously?, Vaccine. 1996; 14 (5): 389-91.

57. Mondiale de la Santé O, Organization WH. Rabies vaccines: WHO position paper-April 2018-Vaccins antirabiques: Note de synthèse de l'OMS-avril 2018. Weekly Epidemiological Record= Relevé épidémiologique hebdomadaire. 2018; 93 (16): 201-19.

58. Ravish HS, Srikanth J, Ashwath Narayana DH, Annadani R, Vijayashankar V, Undi M. Pre-exposure prophylaxis against rabies in children: safety of purified chick embryo cell rabies vaccine (Vaxirab N) when administered by intradermal route. Hum Vaccin Immunother. 2013; 9 (9): 1910-3.
59. Madhusudana S, Anand NP, Shamsundar R. Economical multi-site intradermal regimen with purified chick embryo cell vaccine (Rabipur) prevents rabies in people bitten by confirmed rabid animals. Int J Infect Dis. 2002; 6 (3): 210-4.

60. Jaiiaroensup W, Lang J, Thipkong P, Wimalaratne O, Samranwataya P, Saikasem A, et al. Safety and efficacy of purified Vero cell rabies vaccine given intramuscularly and intradermally. (Results of a prospective randomized trial). Vaccine. 1998; 16 (16): 1559-62.

61. Shin J-H, Sakoda Y, Yano S, Ochiai K, Kida H, Umemura T. Effective prevention against rabies by intracerebral immunization in mice. J Vet Med Sci. 2009; 71 (10): 1331-6.

62. Mills DJ, Lau CL, Fearnley EJ, Weinstein P. The Immunogenicity of a Modified Intradermal Pre-exposure Rabies Vaccination Schedule-A Case Series of 420 Travelers. J Travel Med. 2011; 18 (5): 327-32.

63. Sudarshan M, Madhusudana S, Mahendra B, Narayana DA, Giri MA, Muhamuda K, et al. Boosting effect of purified chick embryo cell rabies vaccine using the intradermal route in persons previously immunized by the intramuscular route or vice versa. Natl Med J India. 2006; 19 (4): 192.

64. Sunden Y, Yano S, Ishida S, Ochiai K, Umemura T. Intracerebral vaccination suppresses the spread of rabies virus in the mouse brain. Microbes Infect. 2010; 12 (14-15): 1163-9.

65. Yoneda A, TuchiYA K, TAKAshimA Y, ArAKAwA T, Tsuji N, Hayashi Y, et al. Protection of mice from rabies by intranasal immunization with inactivated rabies virus. Exp Anim. 2008; 57 (1): 1-9.

66. Yu P, Huang Y, Zhang Y, Tang Q, Liang G. Production and evaluation of a chromatographically purified Vero cell rabies vaccine (PVRV) in China using microcarrier technology. Hu Vacc Immunotherap. 2012; 8 (9): 1230-5.

67. Liniger M, Zuniga A, Naim HY. Use of viral vectors for the development of vaccines. Expert Rev Vaccines. 2007; 6 (2): 255-66.

68. Cook IF. Evidence based route of administration of vaccines. Hum Vaccine. 2008; 4 (1): 67-73.

69. Hanna Jr M, Congdon C, Wust CJ. Effect of antigen dose on lymphatic tissue germinal center changes. Proc Soc Exp Biol Med. 1966; 121 (1): 286-90.

70. Yao C, Kaplan DH. Langerhans cells transfer targeted antigen to dermal DC and acquire MHC-II in vivo. J Invest Dermatol. 2018.

71. Liard C, Munier S, Joulin-Giet A, Bonduelle O, Hadam S, Duffy $\mathrm{D}$, et al. Intradermal immunization triggers epidermal Langerhans cell mobilization required for CD8 T-cell immune responses. J Invest Dermatol. 2012; 132 (3): 615-25.

72. Malissen B, Tamoutounour S, Henri S. The origins and functions of dendritic cells and macrophages in the skin. Nat Rev Immunol. 2014; 14 (6): 417.

73. Engelke L, Winter G, Hook S, Engert J. Recent insights into cutaneous immunization: how to vaccinate via the skin. Vaccine. 2015; 33 (37): 4663-74. 
74. Teunissen $M$, Haniffa $M$, Collin $M$. Insight into the immunobiology of human skin and functional specialization of skin dendritic cell subsets to innovate intradermal vaccination design. Intradermal Immunization: Springer; 2011. 25-76.

75. Levin C, Bonduelle O, Nuttens C, Primard C, Verrier B, Boissonnas A, et al. Critical role for skin-derived migratory DCs and Langerhans cells in TFH and GC responses after intradermal immunization. J Invest Dermatol. 2017; 137 (9): 1905-13.

76. Schmitt D. Cutaneous immune system. Comptes Rendus des Seances de la Société de Biologie et de ses Filiales. 1994; 188 (3): 207-21. 